\title{
Food additives and microbiota
}

\author{
(D) Fatih Gultekin, ${ }^{1}$ (D) Manolya Eser Oner, ${ }^{2}$ (D) Hasan Basri Savas, ${ }^{3}$ (D) Bora Dogan ${ }^{4}$ \\ ${ }^{1}$ Department of Medical Biochemistry, Saglik Bilimleri University Faculty of Medicine, Istanbul, Turkey \\ ${ }^{2}$ Department of Food Engineering, Alanya Alaaddin Keykubat University Faculty of Engineering, Antalya, Turkey \\ 32Department of Medical Biochemistry, Alanya Alaaddin Keykubat University Faculty of Medicine, Antalya, Turkey \\ ${ }^{4}$ Department of Medical Microbiology, Alanya Alaaddin Keykubat University Faculty of Medicine, Antalya, Turkey
}

\begin{abstract}
The use of food additives in food production is inevitable in this modern world. Although only a safe amount of food additives is approved, their safety has always been questioned. To our knowledge, the effects of food additives on microbiota have not been investigated in a detailed manner in the literature so far. In this review, the effects of artificial sweeteners, sugar alcohols, emulsifiers, food colorants, flavor enhancers, thickeners, anticaking agents, and preservatives on microbiota were reviewed. Even though most of the results illustrated negative outcomes, few of them showed positive effects of food additives on the microbiota. Although it is difficult to obtain exact results due to differences in experimental animals and models, said the findings suggest that nonnutritive synthetic sweeteners may lead to glucose intolerance by affecting microbiota and a part of sugar alcohols show similar effects like probiotics.
\end{abstract}

Keywords: Anticaking agents; emulsifiers; food additives; food colorants microbiota; flavor enhancers; glucose intolerance; synthetic sweeteners; sugar alcohols; preservatives; thickeners.

Cite this article as: Gultekin F, Oner ME, Savas HB, Dogan B. Food additives and microbiota. North Clin Istanb 2020;7(2):192-200.

Cood additives are used in the food processing industry to improve color, taste, smell, nutritional value, and shelf-life of food products, which are indicated in labels as "ingredients." Several toxicologic investigations have been conducted before determining permission limits to use food additives in food products. Depending on investigations, safe quantities for animals are determined. Then, these results divided by 100 to obtain a safety level for a human, which is called acceptable daily intake (ADI). According to ADI, the usage amounts of food additives are calculated. There is also a follow-up part of evaluating ADI in case of adverse effects of food additives on humans. Based on this periodical follow-up, ADI values of the additives can be reduced, or the additives can be banned if there are any serious negative side effects. Therefore, food additives with permission are under medium safety levels. Although approved food additives are assumed as safe, emerging of new techniques and research subjects indicate that some of them may still have health concerns.

In recent years, the microbiota is attracting the attention of the researchers. However, the relationship between microbiota and food additives is a new subject to investigate. Human is a superorganism with $10 \% \mathrm{hu}-$ man and $90 \%$ microbial cells [1]. In the meantime, human and microbial genome develops together, thereby their metabolisms and sustainability mixes and becomes inseparable. Microbiota occurs by a combination of bacteria, viruses, and some unicellular eukaryotes.

Presented at the Symposium on "Microbiota and Human Health" organized by Turkish Academy of Sciences, 2017, Ankara, Turkey

Received: October 15, 2018 Accepted: May 21, 2019 Online: July 17, 2019

Correspondence: Dr. Hasan Basri SAVAS. Alanya Alaaddin Keykubat Universitesi Tip Fakultesi, Tibbi Biyokimya Anabilim Dali, Alanya, Antalya, Turkey.

Tel: +90 2425181144 e-mail: hasan.savas@alanya.edu.tr

(c) Copyright 2020 by Istanbul Provincial Directorate of Health - Available online at www.northclinist.com 
The gut microbiota genome codes more than 3.3 million genes, and it is almost 150 times of human genome. In gut microbiota, there have been several species based on these six phyla of bacteria as follows: Firmicutes, Bacteroidetes, Actinobacteria, Proteobacteria, Fusobacteria, and Verrucomicrobia. The intestinal microbiota has a highly dynamic and variable structure depending on genotypes, geography, lifestyle, and age. These changes started in the first year since birth, reached to adults at age 2.5 , and remained constant until senescence [2].

Gut microbiota is very important to human health. It regulates most of the physiological events. Gut microbiota locates in the mucosa layer of the intestine and gives shape. It plays an important role by helping the digestion of pulp in food, synthesizing vitamins and amino acids, helping in energy metabolism and storage, regulating the immune system, growing and developing nerve systems, even regulating our behaviors [2].

In this article, food additives, which are grouped as artificial sweeteners, sugar alcohols, emulsifiers, food colorants, flavor enhancers, thickeners, anticaking agents, and preservatives, are reviewed based on their effects on the microbiota.

\section{Sweeteners}

\section{A) Artificial Sweeteners}

Artificial sweeteners or non-nutritive sweeteners are known as low-calorie and sweet taste compounds. They are generally preferred by people who are on a low-calorie diet or have diabetes. In this part, artificial sweeteners, such as saccharine, sucralose, aspartame, acesulfame-K, neohesperidine DC, and Splenda, were evaluated. There have been few studies regarding artificial sweeteners, and mostly combined effects of two or more of them on microbiota are demonstrated. Therefore, instead of each artificial sweetener, studies are explained under separate titles.

\section{Saccharine (E954), Sucralose (E955), and Aspartame (E951)}

Sucralose, also called trichlorogalactosucrose, tastes 600-650 times sweeter compared to sugar. It has been used as a sweetener in energy-reduced soups, jams, jellos, marmalades, breakfast cereals, and fruit concentrates. Saccharine is an artificial sweetener, which tastes 350 times sweeter than tea sugar. It has been used in food products, such as chips, instant salep, carbonated drinks, flavored fruit juices, fruit nectars, and different diet food products. Basically, aspartame consists of two amino acids and one dipeptide and tastes 150-200 times sweeter than sugar. It is not only used in diet food products but also nonalcoholic beverages, gelatin desserts, low-calorie foods, gums and hot chocolates.

Suez et al. (2014) demonstrated that artificial sweeteners, including saccharine, sucralose and aspartame, induced glucose intolerance in rats, which was related to increasing the number of Bacteroides spp. and bacteria in Clostridiales phylum in the intestine. Thereby, alterations in intestinal microbiota resulted in glucose intolerance induction; non-caloric artificial sweeteners (NAS) did not affect glucose intolerance in germ-free mice and antibiotic - treated rats. In addition, their results indicated that NAS-mediated harmful metabolic effects could be removed with antibiotic therapy, and there is a possibility to transfer harmful effects by transplantation of feces from mice given NAS or by administering anaerobically incubated microbiota under the effect of NAS to microorganism free mice [3]. However, researchers reported that saccharine might affect gut microbiota negatively, and thereby, cause liver inflammation in mice [4]. The results of recent studies investigating the effects of sucralose on glucose hemostasis in humans are controversial. While Grotz et al. showed that sucralose has no effect on glucose metabolism, Romo-Romo et al. revealed that sucralose affects negatively $[5,6]$.

\section{Aspartame (E951) and Acesulfame-K (E950)}

Acesulfame- $\mathrm{K}$ is an artificial sweetener, which tastes 200 times sweeter than sucrose. Generally, it has been used in diet foods, including bakery products, gums, desserts, and non-alcoholic beverages.

Researchers found that rats under low-dose aspartame diet gained less weight compared to rats under high fat and further into the ad libitum water diet. However, lowdose aspartame diet increased fasting glucose level and affected glucose accumulation based on insulin tolerance tests. Metabolites of aspartame into the short chain fatty acid propionate, a bacterial end product and highly gluconeogenic substrate might be the reason for insulin tolerance. Low-dose aspartame consumption increased total bacteria, including Enterobacteriaceae and Clostridium leptum. In addition, combined high fat and aspartame diet consumption increased not only the amount of Roseburia ssp. but also the Firmicutes/Bacteroidetes ratio [7].

In another study, the high-intensity sweeteners - aspartame and acesulfame-K - were investigated to determine the modulation in gut absorption of sugars. 
Aspartame and acesulfame- $\mathrm{K}$ were provided to healthy volunteers for four days, and bacterial community in fecal samples was analyzed using multi-tag pyrosequencing on the $5^{\text {th }}$ day. Results indicated that consumption of aspartame and acesulfame- $\mathrm{K}$ did not increase bacterial abundance profiles and predicted gene function, but they changed bacterial diversity [8]. Moreover, eight weeks of aspartame consumption changed gut microbiota of rats, thereby, increased the blood glucose level and affected the insulin resistance [9]. According to the study of Bian at al. (2017) changes in gut microbiota, and accordingly, weight gain were observed in mice fed with acesulfame potassium for a month [10]. Current data support the notion that non-nutritive sweeteners have metabolic effects due to changes in gut microbiota, which may cause type 2 diabetes and other illnesses [11].

\section{Saccharine (E954) + Neosperidine DC (E959)}

Neosperidine DC is an artificial sweetener and 10001800 times sweeter than sucrose. Neosperidine DC increases the efficacy of other artificial sweeteners when it is used together.

Feeding piglet with Sakkarine (E954) + Neosperidine DC (E959) increased the amount of Lactobacillus in a fecal sample and lactic acid concentration in the gut lumen, which indicated that artificial sweetener might affect the gut microbiota as prebiotics [12].

\section{Splenda}

Splenda is a non-nutritive sweetener, consists of $1 \% \mathrm{w} / \mathrm{w}$ sucralose with glucose $(1 \% \mathrm{w} / \mathrm{w})$ and maltodextrin $(94 \%$ $\mathrm{w} / \mathrm{w})$ as fillers. Research showed that it altered gut microbiota and increased weight gain in rats after 12 weeks of exposure [13].

\section{B) Sugar Alcohols}

Sugar alcohols are organic compounds, a group of polyols, and are typically produced from sugars. The main characteristics of the sugar alcohols are less digestible because they are not totally digested in the small intestine and some of them are fermented in the colon. Some of the sugar alcohols are used as food additives. In this part, maltitol, xylitol, sorbitol and erythritol are evaluated.

\section{Maltitol (E965)}

Maltitol is 10-25\% less sweet than sucrose. Since mouth bacterias are not fed by maltitol, it does not affect teeth rotting negatively and gives cool mouth feel. The energy value of maltitol is half of the sugar. Maltitol is used as a sweetener, humectant, tissue agent, bulking agent and stabilizator in gums, delights and halva products.

The addition of maltitol (E965) $22.8 \mathrm{~g} /$ day to the chocolate products increased the amount of Bifidobacteria. The combination of maltitol and polydextrose increased both Bifidobacteria and Lactobacillus concentration. Besides, it enhanced propionate and butyrate. Results indicated that maltitol was a fermentable product for this kind of microorganisms $[14,15]$.

\section{Xylitol (E967)}

Xylitol is a natural sugar alcohol found in many plants. Xylitol is a low energy sweetener. Even though it has lower energy compared to sugar, it tastes similar. However, it gives cool mouthfeel. Bacterias in the mouth do not use xylitol as an energy source. Therefore, xylitol does not cause teeth rotting and mostly preferred to use in gum production $[16,17]$. It has been reported that xylitol is an eligible component of a diabetic diet [18] and intake of it may be useful in preventing the development of obesity and metabolic disturbances in diet-induced obesity [19].

It has been used in desserts, candies, reduced sugar jams and marmalades, and some bakery products as a sweetener and a humectant. In addition, it has been preferred to use in gum because it reduces teeth rots [16].

Xylitol (E967) is affecting intestinal microbiota. Xylitol consumption is shifted rodent intestinal microbial population from gram-negative to gram-positive bacteria [20]. The effect of xylitol on isoflavonoid of daidzein metabolism and mice intestinal microbiota was observed. The addition of xylitol to daidzein decreased plasma cholesterol level, increased equol in urine and faecal lipids. Researchers found that the amount of Bacteroides was higher in groups fed by xylitol compared to xylitol and daidzein. As a result, there have been potential effects of xylitol on daidzein metabolism via changing the metabolism activity of intestinal microbiota [21].

\section{Sorbitol (E420)}

Sorbitol is a sugar alcohol, which naturally exists in fruits, has a similar structure to sugars. Sorbitol is obtained from glucose and fructose after several chemical treatments and its taste is at least half less sweet compared to regular sugar. It is used in confectionaries, bakery prod- 
ucts and low-calorie foods and gums as a humectant, sweetener, texturizer, bulking agent, and binder. Bacterias in the mouth are not able to use sorbitol as a nutrient source. Thus, it is used as a sweetener in gums while preventing the growth of bacterias, which is essential to mouth and teeth health.

Sorbitol is used by some Lactobacillus species [22] and used as a carbon source by human intestinal Bifidobacteria [23]. Hence, some researchers illustrated that sorbitol is prebiotic [24]. In addition, few in vivo studies indicated that sorbitol has a potential prebiotic effect. Microbial population in rat fed by sorbitol shifted from Gram-negative to Gram-positive [25].

Sarmiento-Rubiano et al. reported that the sorbitol increased the number of Lactobacillus reuteri and helped Lactobacillus sp. AD102 survival. Rats fed with sorbitol had a high butyrate level. However, the asetate/propionate level was low in colon and caecum. Total, HDL, and LDL cholesterol levels were lower in rats who consumed sorbitol, and researchers suggested that this may be due to the low ratio of acetate/propionate [26].

\section{Erythritol (E968)}

Erythritol is a sugar alcohol and widely found in nature. Commercially, erythritol is obtained from glucose using osmophilic yeasts [27]. Erythritol can be used in cheese products, milk powder, desserts made with milk, ice cream, breakfast cereals, processed meat products, desserts made with egg, sauces as a sweetener.

Oral microorganisms do not metabolize erythritol. Ninety percent of erythritol is absorbed in the small intestine by passive diffusion and distributed to other tissues. It is minimally metabolized in the body and most of them excreted with urine [28]. It does not affect glucose and insülin levels $[29,30]$.

Less amount of erythritol is not absorbed, thereby passes through colons and affected by microbiota fermentation. One of the studies indicated that only $10 \%$ of erythritol was suitable for fermentation on rats [31].

Arrigoni et al. (2005) searched erythritol metabolism in human microbiota in vitro conditions. Fresh human intestine microbiotas from three volunteers were incubated with erythritol for $24 \mathrm{~h}$. They evaluated total gas production, hydrogen gas accumulation, $\mathrm{pH}$ changes, short-chain fatty acid production, and erythritol degradation. No gas or fatty acid production was observed. After fermentation, polyol was regained. With these results, researchers have concluded that eritritol is not fermented [32].

\section{C) Emulsifiers}

Emulsifiers have similar effects with detergents due to chemical structure, which consists of a homogeneous mixture of fat and water-based materials. There have been several emulgators produced with natural and artificial ways. In this section, carboxymethyl cellulose and polysorbate 80 are evaluated.

\section{Carboxymethyl Cellulose (E466) and Polysorbate 80 (E433)}

Carboxymethyl cellulose is modified cellulose. It is obtained from its reaction with acetic acid derivatives. It is used as a stabilizator, thickener, and suspension agent in powder form of drinks, fruit yogurts, whipped creams, sauces, diet food products, and ice creams. Polysorbate 80 is a synthetic emulgator, produced using fatty acids and ethylene oxide. It is used as an emulgator in candies, desserts, dairy products, soups, gums and special diet products. Chassaing et al. (2015) illustrated an excessive increase in Ruminococcus gnavus and a decrease in Bacteroidales in rats fed with carboxymethyl cellulose (E466) and polysorbate 80 (E433) for 12 weeks. In addition to microbial changes, there were metabolic syndrome symptoms like intestinal mucus density, low level of inflammation and fat deposition and disorder in glucose metabolism. Emulgator has no negative effects on germ-free mice. These changes occurred by transferring microbiota from mice fed with emulgators to germ-free mice. On the other hand, emulgators increased resistant colitis in IL10-deficient and Toll-like receptor 5 (TLR5)-deficient rats. According to this result, researchers found emulgator enhanced colitis and induced low-level inflammation who has emulgator intolerance [33].

Singh et al. found that glycemic tolerance disorder occurred, blood insulin level increased, hepatic enzyme level enhanced, hepatic mitochondria and gall bladder increased in rats fed with polysorbate 80 . Acetate, propionate and butyrate level was low in rat faecal. High level of DCA and low level of Muc2 RNA expression occurred in the intestinal epithelium, also decrease in mucus thickness and increment in intestine permeability were observed. In addition, intestinal bacteria were in the deep part of the mucus and close to intestinal epithel, thereby bioactive LPS, flagellin levels and LCN2 expression enhanced. Results indicated that there is a relationship between emulgator, such as polysorbate 80 and obesity-related intestinal inflammation and liver disfunction, thereby supported changes in gut microbiota [34]. 
Another study showed that polysorbate 80 changed bile acid level and then affected microbiota composition [35].

\section{D) Food Colorants}

There has been several food colorants with oil-based and water-based properties. In this section, two food colorants are evaluated in nanoparticle structures: silver and titanium dioxide.

\section{Silver (E174) and Titanium Dioxide (E171)}

Silver is a grey color natural metal and obtained from the silver gem. It is used as a colorant in candy and chocolate surface coating. Titanium dioxide is a natural white mineral. It is produced from natural sources using chlorine and sulphuric acid in chemical reactions. It is used as a colorant in gums, chocolates, candies, flavored fruit juices, and some dishes made with yogurt (e.g., haydari).

The effects of silver on gut microbiota were discovered for experimental models with different sizes of silver particles. When zebrafish was fed with $60 \mathrm{~nm}$ and $500 \mathrm{mg} /$ $\mathrm{kg}$ silver-containing food, richness and variety of microbiota did not change. In another study, mice fed with a size of $14 \mathrm{~nm}$ and 4.5 or $9 \mathrm{mg} / \mathrm{kg}$ for 28 days. However, there was no change in the amount of Firmicutes or Bacteroidetes in ceacum. A similar result was determined in mice fed with $110 \mathrm{~nm}$ and $10 \mathrm{mg} / \mathrm{kg}$ for 28 days. There was no change in membership, structure, and diversity of microbiota. In all particles with $10,75,110 \mathrm{~nm}$ and 9, 18, $36 \mathrm{mg} / \mathrm{kg}$ silver increased gram-negative bacteria, and in $10 \mathrm{~nm}$ particle decreased Firmicutes (Lactobacillus) in the ileum. Twenty-eight days of exposure to silver (46, 460 and $4600 \mu \mathrm{g} / \mathrm{L}$ ) caused a reduction of bacterial richness, an increase in dose-dependent Firmicutes and a decrease in Bacteroidetes. The faecal mixture from 33 healthy people was on anaerobic fermentation in vitro in silver nanoparticles environment, and researchers observed there was a change in bacteria population, such as fatty acids [36].

There have been several studies related to titanium dioxide in vitro. These are applied in a dark environment while titanium dioxide nanoparticles are activated with UV light to kill bacteria. In an acidic environment without UV light, titanium dioxide affects the bacteria surface; thereby, electrostatic interaction occurs and then inhibits E. coli cell division [37].

Gut microbiota from healthy donors was treated with $3 \mathrm{mg} / \mathrm{L}$ titanium dioxide for five days in the dark environment of the colon model. Researchers observed phe- notypic changes in short fatty acid production, such as butyric acid, cell hydrophobicity, sugar ingredient of the extracellular polymeric substrate, cell enlargement and electrophoretic mobility of microbiota [38]. Treatment of $E$. coli with titanium dioxide in a dark environment damaged lipopolysaccharides and decreased membrane fluidity [39]. In another study, with the same conditions, reactive oxygen variety production and glutathione levels were decreased, thereby oxidative stress resulted in lipid peroxidation and DNA damage [40].

\section{E) Flavor Enhancers}

Flavor enhancers are used in a wide range of food types to reveal the flavor in foods. Monosodium glutamate is a well-known commonly used flavor enhancer and evaluated in this section.

\section{Monosodium Glutamate (E621)}

Monosodium glutamate (MSG) is used as a flavor enhancer in some food products, such as meatball mixtures, chicken pane mixtures, and meat bouillon. There are still continuing debates about MSG consumption and obesity [41].

Feng et al. investigated the effects of MSG and/or fat on gut microbiota [41]. They fed 32 growing pigs with 3\% MSG basal food for 30 days and then evaluated jejunum, ileum, cecum and colon ingredients. MSG modified gut microbiota diversity, specifically in colons and increased gut microbiota variety. MSG and fat promoted the colonization of microbes related to energy extraction in the gastrointestinal tract. MSG helped colonization of microbes, such as Faecalibacterium prausnitzii and Roseburia.

MSG and fat consumption increased fat accumulation at the back muscle called longissimus dorsi. Consumption of both MSG and fat synergistically enhanced fat accumulation. MSG helped colonisation of microbes; thereby, it is consistent with fat deposition in muscles [41].

\section{E) Thickeners}

Thickeners are substances, which can increase the viscosity of liquids without substantially modifying their other properties. In this part, thickeners - pectin, polydextrose and alginic acid-are evaluated.

\section{Pectin (E440)}

Pectin is a plant-based natural thickener and commer- 
cially produced from orange peels, apple sediments, and beet pulps. It is used as a thickener and emulgator in food products, such as ice cream, jams, marmalades, candies, some beverages, cheese, salep, and yogurt.

Apple derived pectin (E440) decreased weight gain and total cholesterol level when consumed with fatty foods. Fatty foods reduce the amount of Bacteroidetes phylum and increase the amount of Firmicutes phylum. However, pectin addition normalizes these variables. Results indicated that consumption of pectin with fatty foods caused remission of intestinal inflammation, and then, improved intestinal barrier functions [42].

\section{Polydextrose (E1200) (PDX)}

Polydextrose (E1200) produced synthetically from glucose and sorbitol [(E420(i)] by heating with citric acid (E330). It consists of $90 \%$ glucose, $10 \%$ sorbitol, $1 \%$ citric acid and $0.1 \%$ phosphoric acid. Generally, it is used as a bulking agent, viscosity enhancer, humectant, and stabilizator in cookies and halva products.

Polydextrose has prebiotic function due to the change of composition and activity of gut microbiota, and it improves intestine functions $[43,44]$. Polydextrose is slowly fermented, probably used in the distal colon, which will have a positive effect on distal colon illnesses.

Twelve grams of polydextrose affected faecal anaerobes. Species of Bacteroides (B. fragilis, B. vulgatus, and B. intermedius) decreased, Lactobacillus and Bifidobacterium species increased. Faecal weight (wet and dry) and shortchain fatty acids (especially: butyrate, iso-butyrate and acetate) increased, but $\mathrm{pH}$ decreased [43].

When the amount of polydextrose was $8 \mathrm{~g}$, there was no change observed in faecal weight, short-chain fatty acid concentrations, such as propionate and acetate, faecal lactic acid bacteria and bifidobacteria ingredients. Orofacial transit time shortened, $\mathrm{pH}$ decreased, gall bladder acidity and neutral sterol existence varied [44].

\section{Alginic Acid (E400)}

Alginic acid is hydrophilic, colloidal and naturally occurred polysaccharides. It is obtained from some types of sea weeds (Phaeophyceae). It has been used as a stabilizer, viscosity enhancer, gelator, and emulgator in food products, such as jam and jelly.

Gut microbiotas from six Chinese volunteers were completely fermented using different concentrations of

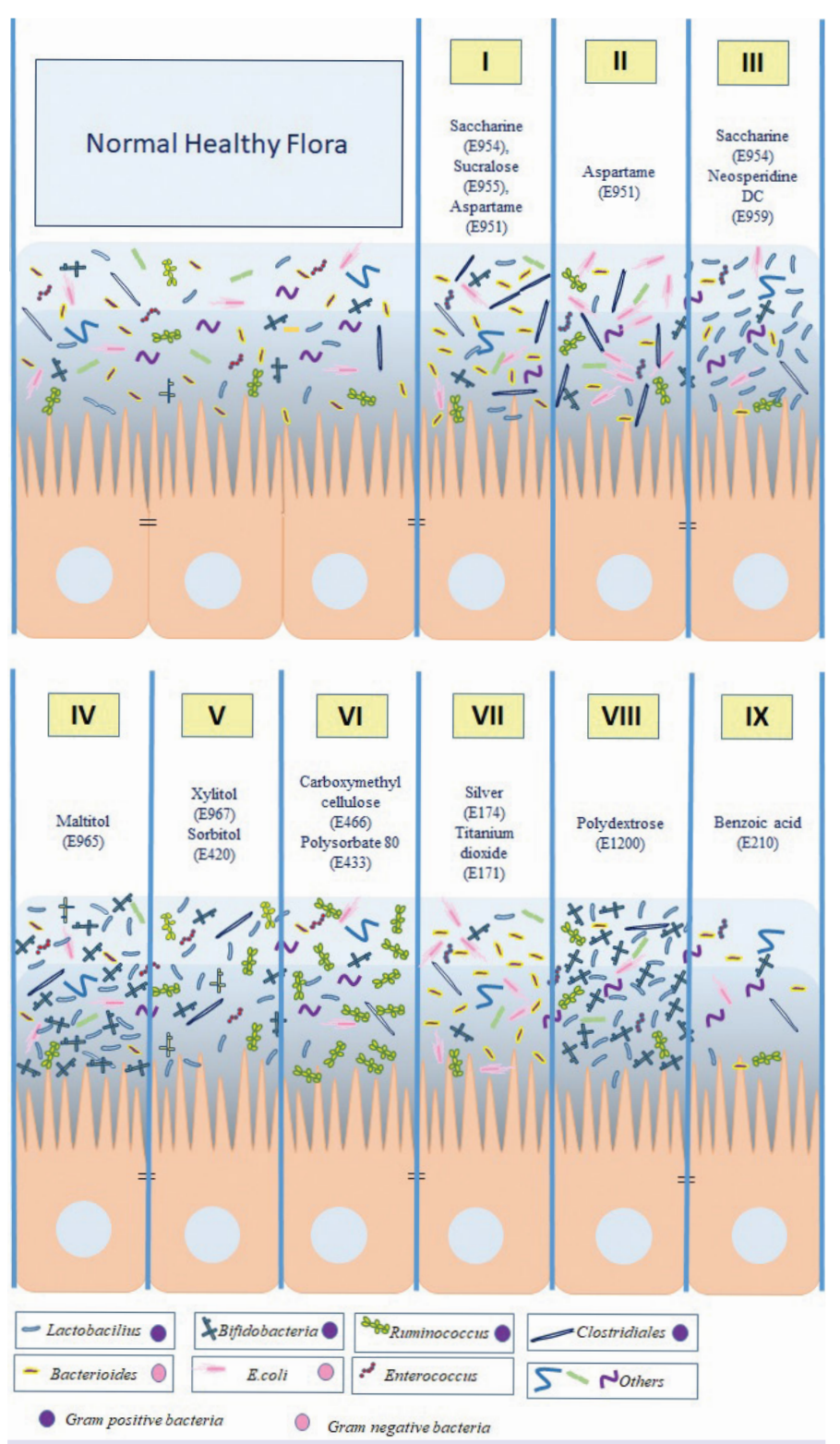

FIGURE 1. The effects of food additives on microbiota are summarized in figure.

Alginic acid. When compared to the control group, the $\mathrm{pH}$ value of fermentation with alginic acid decreased. Fermentation bacterias are Bacteroides ovatus, Bacteroides xylanisolvens, and Bacteroides thetaiotaomicron. During this process, free fatty acids, such as acetic acid, propionic acid and butryic acid, are increased [45].

\section{F) Anticaking Agents}

Anticaking agents prevent a powdered or crystallized form of foods, such as flour and salt from aggregating and agglomerating to maintain a free flow. One of the anticaking agents, bentonite is evaluated in this part. 


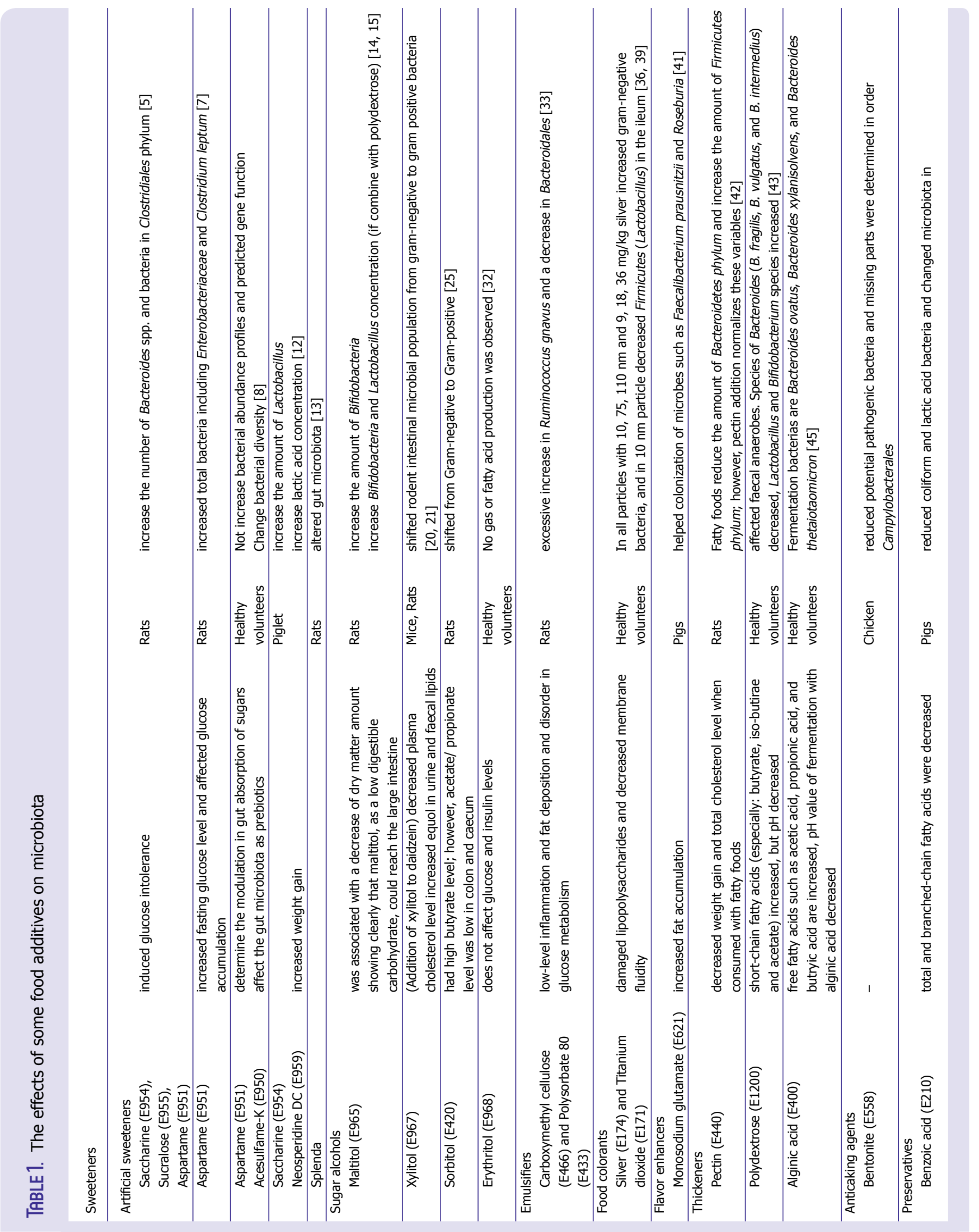




\section{Bentonite (E558)}

Bentonite, a colloidal and hydrated aluminium silicate, is obtained from natural clay varieties. It can contain different amounts of iron and some alcalic materials in commercial forms. It is used in the food industry to prevent agglomeration.

In pet food, it is used for various reseasons, such as stabilizator and lubricant. It extends travel time in the intestine of fowl, thereby increase the effectiveness of feed [46]. It decreases the negative effects of aflatoxin [47].

When chickens were fed with bentonite, it increased egg number and size. Food additives did not affect the microorganism populations negatively in terms of richness and variety. Food additives reduced potential pathogenic bacteria and missing parts were determined in order Campylobacterales [48].

\section{G) Preservatives}

Preservatives are used to maintain an existing condition or prevent damage likely to be brought by chemical (oxidation), physical (temperature, light), or biological (microorganisms) factors. Benzoic acid is one of the preservative types considered in this part.

\section{Benzoic Acid (E210)}

Benzoic acid is a bacteriostatic agent, synthetically obtained and used as an antimicrobial preservative. It is preferred in a wide range of foods, such as sauces, pickles, acidic fruit juices, dried fruits, salty margarine, fruit and vegetable salads, sugary creams, and gums.

Yousaf et al. showed that benzoic acid reduced coliform and lactic acid bacteria and changed microbiota in pigs. The amount of E. coli in young and gram-negative bacteria in adults decreased. High amounts of benzoic acid decreased growth rate $(0.5-0.75 \%)$ in fowl and also ileal coliforms reduced, but caecal lactic acid bacteria increased. $0.1 \%$ ratio increased growth performance. However, a $0.2 \%$ ratio decreased. The same study also indicated that a $0.2 \%$ ratio increased lactic acid bacteria in the ileum and both 0.1 and a $0.2 \%$ ratio decreased coliform bacteria. In different parts of intestine, different short-chain, the fatty acid profile was observed. Benzoate did not affect the $\mathrm{pH}$. Lactate in the craw, D-lactate in the jejunum was enhanced. Caecal total and branchedchain fatty acids were decreased due to the treatment. Lactobacilli increased in jejunum and ileum. Benzoate affected gut microbiota positively by increasing lactic acid bacteria [49].
The effects of food additives on the microbiota are summarized in Figure 1 and Table 1 below.

\section{Conclusion}

In literature, there are few studies related to the effects of food additives on the microbiota. Even though most of the results illustrated negative outcomes, few of them showed positive effects of food additives on the microbiota. Artificial sweeteners are highly likely to destroy glucose tolerance and support weight gaining by affecting microbiota negatively. Most of the sugar alcohols are fermentable by bacterias and may show similar properties with prebiotics. Due to differences in experimental animals and models, there is not an exact result obtained. Thus, further studies are needed to evaluate the effects of food additives on gut microbiota.

Conflict of Interest: No conflict of interest was declared by the authors.

Financial Disclosure: The authors declared that this study has received no financial support.

Authorship Contributions: Concept - FG, HBS; Design - FG, BD; Supervision - FG, MEO; Materials - MEO, HBS; Data collection and/ or processing - BD, MEO; Analysis and/or interpretation - FG, HBS; Literature review - MEO, HBS; Writing - BD, HBS, MEO, FG; Critical review - FG, BD.

\section{REFERENCES}

1. Lederberg J. Infectious history. Science 2000;288:287-93. [CrossRef]

2. Jin Y, Wu S, Zeng Z, Fu Z. Effects of environmental pollutants on gut microbiota. Environ Pollut 2017;222:1-9. [CrossRef]

3. Suez J, Korem T, Zeevi D, Zilberman-Schapira G, Thaiss CA, Maza O, et al. Artificial sweeteners induce glucose intolerance by altering the gut microbiota. Nature 2014;514:181-6. [CrossRef]

4. Bian X, Tu P, Chi L, Gao B, Ru H, Lu K. Saccharin induced liver inflammation in mice by altering the gut microbiota and its metabolic functions. Food Chem Toxicol 2017;107:530-9. [CrossRef]

5. Romo-Romo A, Aguilar-Salinas CA, Brito-Córdova GX, Gómez-Díaz RA, Almeda-Valdes P. Sucralose decreases insulin sensitivity in healthy subjects: a randomized controlled trial. Am J Clin Nutr 2018;108:48591. [CrossRef]

6. Grotz VL, Pi-Sunyer X, Porte D Jr, Roberts A, Richard Trout J. A 12 week randomized clinical trial investigating the potential for sucralose to affect glucose homeostasis. Regul Toxicol Pharmacol 2017;88:22-33.

7. Palmnäs MS, Cowan TE, Bomhof MR, Su J, Reimer RA, Vogel HJ, et al. Low-dose aspartame consumption differentially affects gut microbiota-host metabolic interactions in the diet-induced obese rat. PLoS One 2014;9:e109841. [CrossRef]

8. Frankenfeld CL, Sikaroodi M, Lamb E, Shoemaker S, Gillevet PM. High-intensity sweetener consumption and gut microbiome content and predicted gene function in a cross-sectional study of adults in the United States. Ann Epidemiol 2015;25:736-42. [CrossRef]

9. Palmnäs MS, Cowan TE, Bomhof MR, Su J, Reimer RA, Vogel HJ, et al. Low-dose aspartame consumption differentially affects gut microbio- 
ta-host metabolic interactions in the diet-induced obese rat. PLoS One 2014;9:e109841. [CrossRef]

10. Bian X, Chi L, Gao B, Tu P, Ru H, Lu K. The artificial sweetener acesulfame potassium affects the gut microbiome and body weight gain in CD-1 mice. PLoS One 2017;12:e0178426. [CrossRef]

11. Pepino MY. Metabolic effects of non-nutritive sweeteners. Physiol Behav 2015;152:450-5. [CrossRef]

12. Daly K, Darby AC, Hall N, Nau A, Bravo D, Shirazi-Beechey SP. Dietary supplementation with lactose or artificial sweetener enhances swine gut Lactobacillus population abundance. Br J Nutr 2014;111 Suppl 1:S30-5. [CrossRef]

13. Abou-Donia MB, El-Masry EM, Abdel-Rahman AA, McLendon RE, Schiffman SS. Splenda alters gut microflora and increases intestinal p-glycoprotein and cytochrome p-450 in male rats. J Toxicol Environ Health A 2008;71:1415-29. [CrossRef]

14. Beards E, Tuohy K, Gibson G. A human volunteer study to assess the impact of confectionery sweeteners on the gut microbiota composition. Br J Nutr 2010;104:701-8. [CrossRef]

15. Oku T, Akiba M, Lee MH, Moon SJ, Hosoya N. Metabolic fate of ingested [14C]-maltitol in man. J Nutr Sci Vitaminol (Tokyo) 1991;37:529-44. [CrossRef]

16. Lynch H, Milgrom P. Xylitol and dental caries: an overview for clinicians. J Calif Dent Assoc 2003;31:205-9.

17. Campus G, Cagetti MG, Sacco G, Solinas G, Mastroberardino S, Lingström P. Six months of daily high-dose xylitol in high-risk schoolchildren: a randomized clinical trial on plaque $\mathrm{pH}$ and salivary mutans streptococci. Caries Res 2009;43:455-61. [CrossRef]

18. Goto Y, Anzai M, Chiba M, Ohneda A, Kawashima S. Clinical effects of xylitol on carbohydrate and lipid metabolism in diabetes. Lancet 1965;2:918-21. [CrossRef]

19. Amo K, Arai H, Uebanso T, Fukaya M, Koganei M, Sasaki H, et al. Effects of xylitol on metabolic parameters and visceral fat accumulation. J Clin Biochem Nutr 2011;49:1-7. [CrossRef]

20. Tamura M, Hoshi C, Hori S. Xylitol affects the intestinal microbiota and metabolism of daidzein in adult male mice. Int J Mol Sci 2013;14:23993-4007. [CrossRef]

21. Salminen S, Salminen E, Koivistoinen P, Bridges J, Marks V. Gut microflora interactions with xylitol in the mouse, rat and man. Food Chem Toxicol 1985;23:985-90. [CrossRef]

22. Yebra MAJ, Pérez-Martı Nez G. Cross-talk between the L-sorbose and D-sorbitol (D-glucitol) metabolic pathways in Lactobacillus casei. Microbiology 2002;148:2351-9. [CrossRef]

23. Rhodes MW, Kator H. Sorbitol-fermenting bifidobacteria as indicators of diffuse human faecal pollution in estuarine watersheds. J Appl Microbiol 1999;87:528-35. [CrossRef]

24. Farnworth ER. In: Wildman REC, editor. Handbook of Nutraceutilcals and Functional Foods. 2001; 407 - 422. Boca Raton, FL: CRC Press.

25. Salminen S, Salminen E, Bridges J, Marks V. The effects of sorbitol on the gastrointestinal microflora in rats. Z Ernahrungswiss 1986;25:91-5.

26. Sarmiento-Rubiano LA, Zúñiga M, Pérez-Martínez G, Yebra MJ. Dietary supplementation with sorbitol results in selective enrichment of lactobacilli in rat intestine. Res Microbiol 2007;158:694-701. [CrossRef]

27. Goossens J, Röper H. Erythritol: a new sweetener. Food Sci Technol Today 1994;8:144-9.

28. Bernt WO, Borzelleca JF, Flamm G, Munro IC. Erythritol: a review of biological and toxicological studies. Regul Toxicol Pharmacol 1996;24:S191-7. [CrossRef]

29. Bornet FR, Blayo A, Dauchy F, Slama G. Plasma and urine kinetics of erythritol after oral ingestion by healthy humans. Regul Toxicol Pharmacol 1996;24:S280-5. [CrossRef]

30. Ishikawa M, Miyashita M, Kawashima Y, Nakamura T, Saitou N, Modderman J. Effects of oral administration of erythritol on patients with diabetes. Regul Toxicol Pharmacol 1996;24:S303-8. [CrossRef]

31. Noda K, Oku T. Metabolism and disposition of erythritol after oral administration to rats. J Nutr 1992;122:1266-72. [CrossRef]

32. Arrigoni E, Brouns F, Amadò R. Human gut microbiota does not ferment erythritol. Br J Nutr 2005;94:643-6. [CrossRef]

33. Chassaing B, Koren O, Goodrich JK, Poole AC, Srinivasan S, Ley RE, Gewirtz AT. Dietary emulsifiers impact the mouse gut microbiota promoting colitis and metabolic syndrome. Nature 2015;519:92-6. [CrossRef]

34. Singh RK, Wheildon N, Ishikawa S. Food Additive P-80 Impacts Mouse Gut Microbiota Promoting Intestinal Inflammation, Obesity and Liver Dysfunction. SOJ Microbiol Infect Dis 2016;4. [CrossRef]

35. Dimitrijevic D, Shaw AJ, Florence AT. Effects of some non-ionic surfactants on transepithelial permeability in Caco-2 cells. J Pharm Pharmacol 2000;52:157-62. [CrossRef]

36. Mercier-Bonin M, Despax B, Raynaud P, Houdeau E, Thomas M. Mucus and microbiota as emerging players in gut nanotoxicology: The example of dietary silver and titanium dioxide nanoparticles. Crit Rev Food Sci Nutr 2018;58:1023-32. [CrossRef]

37. Zhukova LV, Kiwi J, Nikandrov $\mathrm{VV}$. $\mathrm{TiO}_{2}$ nanoparticles suppress Escherichia coli cell division in the absence of UV irradiation in acidic conditions. Colloids Surf B Biointerfaces 2012;97:240-7. [CrossRef]

38. Taylor AA, Marcus IM, Guysi RL, Walker SL. Metal oxide nanoparticles induce minimal phenotypic changes in a model colon gut microbiota. Environ Eng Sci 2015;32:602-12. [CrossRef]

39. Liu P, Duan W, Wang Q, Li X. The damage of outer membrane of Escherichia coli in the presence of $\mathrm{TiO}_{2}$ combined with UV light. Colloids Surf B Biointerfaces 2010;78:171-6. [CrossRef]

40. Kumar A, Pandey AK, Singh SS, Shanker R, Dhawan A. Engineered $\mathrm{ZnO}$ and $\mathrm{TiO}(2)$ nanoparticles induce oxidative stress and DNA damage leading to reduced viability of Escherichia coli. Free Radic Biol Med 2011;51:1872-81. [CrossRef]

41. Feng ZM, Li TJ, Wu L, Xiao DF, Blachier F, Yin YL. Monosodium LGlutamate and Dietary Fat Differently Modify the Composition of the Intestinal Microbiota in Growing Pigs. Obes Facts 2015;8:87-100.

42. Jiang T, Gao X, Wu C, Tian F, Lei Q, Bi J, et al. Apple-Derived Pectin Modulates Gut Microbiota, Improves Gut Barrier Function, and Attenuates Metabolic Endotoxemia in Rats with Diet-Induced Obesity. Nutrients 2016;8:126. [CrossRef]

43. Jie Z, Bang-Yao L, Ming-Jie X, Hai-Wei L, Zu-Kang Z, Ting-Song W, et al. Studies on the effects of polydextrose intake on physiologic functions in Chinese people. Am J Clin Nutr 2000;72:1503-9. [CrossRef]

44. Hengst C, Ptok S, Roessler A, Fechner A, Jahreis G. Effects of polydextrose supplementation on different faecal parameters in healthy volunteers. Int J Food Sci Nutr 2009;60 Suppl 5:96-105. [CrossRef]

45. Li M, Li G, Shang Q, Chen X, Liu W, Pi X, et al. In vitro fermentation of alginate and its derivatives by human gut microbiota. Anaerobe 2016;39:19-25. [CrossRef]

46. Damiri H, Chaji M, Bojarpour M, Eslami M, Mamoei M. The effect of sodium betonites on economic value of broiler chickens diet. J Anim Vet Adv 2010;9:2668-70. [CrossRef]

47. Moghaddam HN, Jahanian R, Najafabadi HJ, Madaeni M. Influence of dietary zeolite supplementation on the performance and egg quality of laying hens fed varying levels of calcium and nonphytate phosphorus. J Biol Sci 2008;8:328-34. [CrossRef]

48. Prasai TP, Walsh KB, Bhattarai SP, Midmore DJ, Van TT, Moore RJ, et al. Biochar, Bentonite and Zeolite Supplemented Feeding of Layer Chickens Alters Intestinal Microbiota and Reduces Campylobacter Load. PLoS One 2016;11:e0154061. [CrossRef]

49. Yousaf MS, Goodarzi Boroojeni F, Vahjen W, Männer K, Hafeez A, Ur-Rehman H, et al. Encapsulated benzoic acid supplementation in broiler diets influences gut bacterial composition and activity. Br Poult Sci 2017;58:122-31. [CrossRef] 